\title{
Análisis y evaluación de la generación de iconos mentales en personas invidentes a partir de la percepción virtual táctil utilizando realidad virtual y sistemas hápticos
}

\section{Analysis and evaluation of the generation of mental icons in blind people from the virtual tactile perception using virtual reality and haptic systems}

Raquel Espinosa Castañeda

Profesor Investigador de tiempo completo, Escuela de Ciencias de la Comunicación (Universidad Autónoma de San Luis Potosí)

Hugo Iván Medellín Castillo

Profesor Investigador de Tiempo Completo, Facultad de Ingeniería (Universidad Autónoma de San Luis Potosí)

Fecha de recepción: 1 de mayo de 2014

Fecha de revisión: 17 de julio de 2014

Para citar este artículo: Espinosa Castañeda, R. y Medellín Castillo, H. I. (2014): Análisis y evaluación de la generación de iconos mentales en personas invidentes a partir de la percepción virtual táctil utilizando realidad virtual y sistemas hápticos, Icono 14, volumen (12), pp. 295-317. doi: 10.7195/ri14.v12i2.695 


\section{Resumen}

Las representaciones del espacio circundante para videntes e invidentes se definen mediante el proceso de la percepción sensorial. La percepción háptica (táctil) no depende de la visual; a través del sentido del tacto activo es posible extraer la información necesaria para generar representaciones icónicas de los objetos. El presente trabajo de investigación evalúa y analiza el proceso de percepción virtual táctil para la construcción de iconos mentales de objetos tridimensionales explorados a través del Sistema CIGI (Cinematográfico Interactivo para Gente Invidente), el cual hace uso de tecnologías avanzadas en computación, realidad virtual y sistemas hápticos. El objetivo es analizar y entender la influencia de la percepción virtual táctil en la generación de iconos mentales en personas invidentes. Para lograr lo anterior, se utiliza una metodología experimental basada en las experiencias de exploración táctil de figuras geométricas $3 D$ en un grupo de personas invidentes mediante el sistema CIGI. Los resultados demuestran que la construcción de iconos mentales a partir de percepciones virtuales táctiles es posible en personas invidentes.

Palabras clave: Comunicación - Psicología - Realidad Virtual - Educación

\section{Abstract}

The representation of the surrounding space by sighted and blind people are defined by the means of the sensory perception. Haptic (tactile) perception does not depend on visual perception; by means of the active touch sense it is possible to extract the necessary information to generate symbolic representations of objects. This research work evaluates and analyses the virtual haptic perception process for the construction of mental icons of three-dimensional objects that are explored by means of the CIGI (Interactive Cinema for Blind People) System, which makes use of advanced technologies in computing science, virtual reality and haptic systems. The aim is to analyze and understand the influence of tactile perceptions on the generation of mental icons in blind people. For this purpose, an experimental methodology, based on the experiences of the tactile exploration of 3D shapes of a group of blind people by means of the CIGI system, is used.

Key Words: Mental icon - Virtual tactile perception - Blind people - Cinema for the blind - Interactive Cinema for Blind People (CIGI) system.

ICONO14 | Año 2014 Volumen 12 N² 2 | ISSN: 1697-8293 | DOI: ri14.v12i2.695 


\section{Introducción}

Los productos comunicativos se han enfocado tradicionalmente a estimular los sentidos del oído y la vista, incluso a los medios masivos de comunicación se les ha llamado medios audiovisuales. Lo anterior implica dejar rezagados al resto de los sentidos, limitando la integración en el ámbito sociocultural de personas con capacidades diferentes que carecen del sentido de la vista y/u oído. Sin embargo, la imagen desde el punto de vista neurálgico de su concepción, no está limitada a la imagen visual sino que puede ser percibida por todos los sentidos. Una forma poco explorada de generar iconos mentales es mediante la percepción háptica o percepción táctil, la cual depende del sentido del tacto, y que en personas invidentes resulta de vital importancia. Una persona invidente depende principalmente de su sentido del tacto y del oído para obtener conocimiento de él mismo y de su medio ambiente. Sin embargo, la aproximación del lenguaje táctil a los medios masivos de comunicación aún está limitada en cuanto al manejo en la emisión de mensajes, lenguaje al cual está acostumbrado el ciego y que le sería de gran utilidad para comprender mejor ese mundo visual de los medios. Es entendible esa falta de preocupación por las características propias de los medios denominados audiovisuales; ya que por ser visuales, no se enfocan a lo táctil.

Recientemente los autores han propuesto el desarrollo de la comunicación audiovisual para gente invidente, pero con la adición de la percepción virtual táctil de su entorno, lo cual se puede lograr mediante el uso de las tecnologías modernas de computación, realidad virtual y sistemas hápticos. Sin embargo, es necesario estudiar y entender el proceso de generación de iconos mentales a partir de iconos táctiles. Por tanto, en este trabajo se presenta un estudio del proceso de generación de iconos mentales a partir de iconos táctiles generados de la exploración virtual táctil de objetos tridimensionales utilizando el sistema CIGI (Cinematográfico Interactivo para Gente Invidente).

\section{Icono}

La palabra icono procede de la palabra griega eikon que significa imagen o representación. En el campo de la semiología y la semiótica, un icono es un signo vi-

DOI: ri14.v12i2.695 | ISSN: 1697-8293 | Año 2014 Volumen 12 № 2 | ICONO14 
sual que representa otro objeto semejante a él. Gracias a esta relación de similitud, el icono puede sustituir a lo que representa. La imagen por su parte procede del latín imago, que se concibe como un sinónimo de representación visual, aunque también se puede aplicar como extensión a otros tipos de percepción, como imágenes auditivas, olfativas, táctiles, kinestésicas, etc. Por su parte, el icono no sólo es un signo visual, sino sensorial que permite la representación de los objetos en la mente del que se expone a ese signo, idea que se reafirma con el planteamiento saussureano al esbozar que:

"El carácter fisico de nuestras imágenes acústicas aparece claramente cuando observamos nuestro propio lenguaje. Sin mover los labios ni la lengua, podemos hablarnos a nosotros mismos o recitarnos mentalmente un poema. Y porque las palabras de la lengua son para nosotros imágenes acústicas, hay que evitar hablar de los «fonemas» de que están compuestas. Este término que implica una idea de acción vocal, no puede convenir más que a la palabra hablada, a la realización de la imagen interior en el discurso. (,..., Esta definición plantea una importante cuestión de terminología. Llamamos signo a la combinación del concepto y de la imagen acústica" (Saussure, 1998:102).

La imagen acústica es por antonomasia la apelación natural de la palabra, por su parte la imagen táctil será entonces por excelencia la representación natural del objeto tocado. Por tanto si un cubo (objeto geométrico) es llamado signo, será porque lleva en sí el concepto de un «cubo», de tal manera que la unión de la idea o concepto y la parte sensorial auditiva y táctil, implicará la representación icónica de su totalidad.

El padre de la semiótica moderna, Pierce, considera que el icono es un signo que se caracteriza por guardar una relación de semejanza con lo que representa, lo cual concuerda con su concepción griega eikon. Isidro Moreno afirma que "para leer un icono adecuadamente es necesario poseer una experiencia y conocimiento similares de lo representado" (Moreno, 2003:125); es decir, para que una persona pueda representar mentalmente un objeto, por ejemplo un castillo, es necesario que lo conozca previamente. Así que "la semejanza que guarda un icono con el objeto, el

ICONO14 | Año 2014 Volumen 12 N² 2 | ISSN: 1697-8293 | DOI: ri14.v12i2.695 
elemento o la idea que representa depende del grado de iconocidad del icono" (Moreno, 2003:126). Lo anterior debe entenderse desde el aprendizaje icónico como se presenta en la siguiente sección.

\section{Aprendizaje icónico mediante la percepción táctil}

El psicólogo, filósofo y teórico David Katz, se enfocó al sentido del tacto como fuente psicológica de conocimiento planteando que "los conocimientos suministrados por el tacto tienen el más fecundo carácter de realidad" (Correa, 2006); distinguiendo el potencial del tacto activo al estudiar el reconocimiento de la configuración de las superficies a través del movimiento de la mano y considerando que se pueden reconocer superficies a través del movimiento de la misma. "Los dedos en su conjunto natural, colaboran con el tacto y para la conciencia representan un órgano táctil unitario" (Katz, 1930), por lo que al mover la mano mientras se toca algo, el sujeto aprende al ser consciente de las propiedades del objeto.

El modelo icónico de aprendizaje implica el uso de imágenes o dibujos, adquiriendo una importancia progresiva a medida que el niño crece y conoce los conceptos y principios no demostrables fácilmente. De acuerdo al psicólogo y pedagogo Jerome Bruner, "la representación icónica echa mano de la imaginación" (Arambu$\mathrm{ru}, 2004: 2)$. Se vale de imágenes y esquemas espaciales más o menos complejos para representar el entorno. Según Bruner, es necesario haber adquirido un nivel determinado de destreza y práctica motrices, para que se desarrolle la imagen correspondiente. Sin embargo, si las imágenes visuales no las puede ver una persona invidente, entonces su aprendizaje y generación de iconos mentales dependerá de la adquisición de conceptos y principios por medio de los otros sentidos.

\subsection{Representaciones simbólicas sensoriomotoras}

Piaget (1946) menciona en su teoría del desarrollo, citado en Psicología de la Ceguera (Rosa y 0chaíta, 1993), que "el niño empieza a manifestar conjuntamente ciertas capacidades representativas y simbólicas, aproximadamente en la segunda mitad del primer año, cuando termina el periodo denominado inteligencia sensoriomotora". Estas habilidades se empiezan a desarrollar cuando el niño ya hace uso de

DOI: ri14.v12i2.695 | ISSN: 1697-8293 | Año 2014 Volumen 12 № 2 | ICONO14 
significantes y significados, siendo ambos como las dos partes de lo que es el signo lingüístico. La relación entre significantes y significados no es natural, es arbitraria. Un ejemplo de esto es que la palabra "perro" nada tiene que ver con el perro en realidad, se le ha asignado esa imagen auditiva. La palabra es el significado y su huella psíquica es el significante, ya que el lector podría pensar en un cierto tipo de raza canina diferente a otra raza que otra persona pensaría al escuchar ese vocablo.

"Así entonces las representaciones de los objetos y del espacio en que se sitúan, la capacidad de evocarlos cuando no están presentes, se originan en la acción sensoriomotora que el niño realiza sobre ellos, en concreto en los mecanismos acomodativos implicados en la imitación" (Rosa y 0chaíta, 1993). Es entonces cuándo, el niño aparte de empezar a interesarse por los objetos y las personas, comienza a mostrar ese interés de comunicarse con ellas y descubrir las características de los objetos. Por su parte, "los niños invidentes son capaces de representar los objetos percibidos táctil y auditivamente, si bien con un retraso de entre 8 y 32 meses cuando se les compara con los videntes. Este retraso es menor cuando las imágenes se originan mediante la exploración táctil del objeto que cuando se trata de identificar éste por los datos auditivos" (Rosa y Ochaíta, 1993).

En resumen, se puede decir que la función simbólica surge y crece con la interacción social, pues gracias a ésta el niño será capaz de incorporar todo el sistema de símbolos que le proporciona la sociedad y su cultura, aunque el retraso en niños invidentes sea notorio. Sin embargo se puede decir que éstos últimos también pueden desarrollar imágenes o iconos mentales mediante el tacto.

\subsection{Percepción háptica}

Uno de los experimentos realizados en 1966 por Gibson, plantea que "nuestra experiencia del mundo está basada en una combinación de sensación táctil y kinestésica, y a esta combinación se le denomina percepción háptica" (Gibson, 1966). Gibson fue el pionero en plantear la percepción háptica como tal. Para ello realizó un experimento que consistió en el reconocimiento de 10 moldes con la mano, estos moldes tenían diferentes formas y tamaños, y se los proporcionó a sujetos videntes e invidentes para conocer si era posible o no acertar en dicho reconocimiento. Como

ICONO14 | Año 2014 Volumen 12 N² | ISSN: 1697-8293 | DOI: ri14.v12i2.695 
resultado concluyó que la percepción de formas pequeñas presentaba variaciones según el modo en que el individuo lo había explorado. Además mencionó la existencia de una equivalencia parcial entre los aspectos visuales y la representación háptica de los objetos, siendo evidente que "la cualidad o modalidad sensorial nos permite reconocer un objeto con solo tocarlo antes de verlo o viceversa" (Gibson, 1966).

Ante esta información se puede inferir que la percepción háptica permite obtener información del entorno, tanto a videntes como a invidentes, tomando en cuenta que en el caso de los invidentes "el cerebro tiene la capacidad de refuncionalizar áreas que están asociadas a funciones visuales, permitiéndoles emitir una respuesta a información táctil y auditiva" (Merabet y Pascual,1993).

\subsection{Icono háptico}

La modalidad táctil tiene la misma importancia que la visión al proceso perceptivo, por lo que el tacto es utilizado como acto de conocimiento que implica tiempo para realizar una acción, recoger información y procesarla. Abraham Moles propone que "la imagen es una cristalización de lo real sensorial" (1991). A partir de ésta propuesta surge la necesidad de establecer un término más específico para la imagen, por lo que en 1993 los investigadores integrantes del grupo $\mu$ utilizaron el concepto de ícono en lugar de imagen, tomando como base para hacerlo la existencia latente de otras realidades sensoriales. Mediante este concepto de icono se puede decir que la información que el ser humano dilucida mentalmente a través de los procesos sensitivos, es posible integrarla gracias a la conciencia, formando iconos mentales hápticos. Por lo que si el icono Pierciano es un signo que se caracteriza por guardar una relación de semejanza con lo que representa, y si la imagen es la cristalización de lo real sensorial, entonces el ciego que toca un objeto generará una representación mental semejante al objeto mismo, formando a su vez un icono háptico.

\subsection{Icono mental háptico}

Para poder percibir o construir la noción de un objeto es necesario procesar la información y reconocerla, para lo cual se sigue un proceso secuencial que consiste en: a) el paso de estímulo a figura, donde la figura es producto de un proceso

DOI: ri14.v12i2.695 | ISSN: 1697-8293 | Año 2014 Volumen 12 № 2 | ICONO14 
sensorial; b) el paso de figura a forma, donde toda figura es una forma; c) el paso del objeto al signo, donde la función perceptiva alcanza la función semiótica, es decir es una estructura cognitiva. "Al pasar por este proceso perceptual y cognitivo, la imagen puede llegar a generar una realidad inmaterial, como imagen mental" (Correa, 2008). Y si en su acepción más básica una imagen es un ícono, se puede estipular que a partir de este fundamento se entiende que en la estructura cognitiva del proceso secuencial, el icono táctil se puede comparar con el icono visual, pues ambos funcionan como un referente comunicacional de la representación del mundo, por ello es que le hemos llamado icono mental háptico.

\subsection{Icono mental en personas ciegas}

Merleau-Ponty menciona que para el ciego, "su mundo se va modificando a medida que se mueve, y le permite comprender mejor el espacio" (1960). Estudios sobre la formación de imágenes mentales en ciegos de nacimiento, observan que las personas ciegas de nacimiento pasan por diferentes etapas del desarrollo. En las primeras etapas el niño ciego presenta dificultades en tareas que implican realizar transformaciones de imágenes mentales. Sin embargo, Merleau-Ponty agregó "que cuando el niño se acerca a la etapa de operaciones formales, alcanza un nivel de resolución igual al de los niños videntes" (1960). Este concepto es amplio, pues implica que la representación mental puede lograrse aunque la persona no tenga la posibilidad de ver, lo cual confirma que los ciegos tienen la capacidad de crear iconos mentales.

\section{Realidad virtual y sistemas hápticos}

El incremento en las tecnologías computacionales en las últimas cuatro décadas, ha permitido el desarrollo de sistemas modernos de graficación, en los cuales se pueden representar ambientes virtuales muy cercanos a la realidad. La mayoría de los sistemas computacionales modernos consideran al sentido de la vista como el sentido más importante. Isidro Moreno considera que "en la realidad virtual, el espacio virtual actúa como macroicono natural que permite vivir experiencias vicarias" (Moreno, 2003:129). Por tanto, si se incorpora el sentido del tacto a la realidad virtual, se enriquece la imagen visual llegando a formar un icono mental táctil, objetivo central del presente trabajo de investigación.

ICONO14 | Año 2014 Volumen 12 N² 2 | ISSN: 1697-8293 | DOI: ri14.v12i2.695 


\subsection{Realidad virtual}

El término Realidad Virtual (RV) es en sí mismo paradójico ya que se compone de dos conceptos prácticamente opuestos: Real que es aquello que tiene existencia verdadera y efectiva, y Virtual que tiene virtud de producir un efecto, aunque no lo produce en forma presente; frecuentemente en oposición a lo efectivo o real. El término RV por tanto puede llevar al significado confuso de "Realidad No Real". Por esta razón algunos investigadores prefieren usar otros términos como: ciberespacio, realidad artificial, ambientes sintéticos, ambientes virtuales, etc.

\subsection{Sistemas hápticos}

La palabra háptico proviene de la palabra griega haptesthai que significa tocar. El renderizado háptico es el nombre que se le da al proceso de sentir o tocar objetos virtualmente. Esto involucra retroalimentación táctil para sentir propiedades tales como textura superficial y retroalimentación kinestésica para sentir las formas, tamaños y peso de los objetos. Similar a la graficación computacional, el renderizado háptico computacional provee la proyección interactiva de objetos a las personas, pero con la diferencia de que los objetos virtuales pueden ser palpados mediante un dispositivo háptico.

Los dispositivos o sistemas hápticos se comportan como un pequeño robot que sirve como interface computacional e intercambia energía mecánica con el usuario. Aunque estas interfaces pueden estar en contacto con cualquier parte del cuerpo humano del usuario, las interfaces manuales han sido las más desarrolladas y utilizadas hasta la fecha. Una forma de clasificar los dispositivos hápticos es de acuerdo a su localización o fijación: móviles, fijos, vestibles y exoskeletons. Los sistemas hápticos también se pueden clasificar de acuerdo al número de grados de libertad (DOF) de movimiento o fuerza presentes en la interfaz dispositivo-humano. Existen actualmente en el mercado varios dispositivos hápticos, entre los que destacan el Phantom Omni y el Phantom Desktop de Sensable ${ }^{\circledR}$, el Falcon de Novint ${ }^{\circledR}$, y el Virtuose de Haption ${ }^{\circledR}$ (Figura 1).

DOI: ri14.v12i2.695 | ISSN: 1697-8293 | Año 2014 Volumen 12 № 2 | ICONO14 


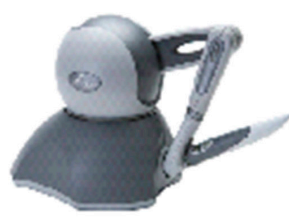

(a)

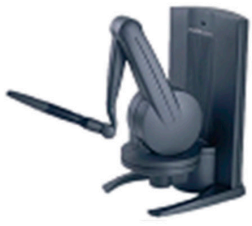

(b)

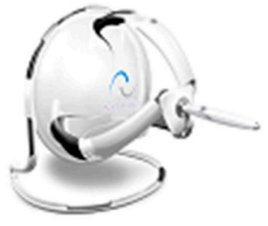

(c)

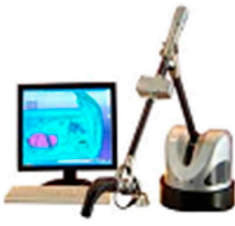

(d)

Figura 1: Sistemas hápticos comerciales: a) phantom omni,

b) phantom desktop, c) falcon, d) virtuose.

\subsection{Aplicaciones}

Las áreas de aplicación de los sistemas de realidad virtual y sistemas hápticos incluyen:

- Medicina: Desarrollo de sistemas virtuales para el diseño de prótesis e implantes, sistemas de cirugía por computadora, entrenamiento quirúrgico, rehabilitación, tratamientos o terapias para cierto tipo de enfermedades como las fobias.

- Ingeniería: Desarrollo de sistemas de diseño y manufactura virtuales, simulación virtual de procesos industriales, entrenamiento virtual de operarios, etc.

- Entretenimiento: Videojuegos y simuladores que permiten al usuario sentir y manipular objetos virtualmente.

- Arte: exhibiciones virtuales de arte, museos virtuales, conciertos virtuales, esculpido virtual de objetos, etc.

- Ciencia: Representación y simulación virtual de fenómenos físicos, biológicos, químicos, visualización de información científica.

- Educación: Creación de escenarios a escala nano, micro, macro o astronómico, para proporcionar a los estudiantes el experimentar diversos fenómenos en un mundo virtual. 
En el área de la medicina se han desarrollado sistemas de cirugía virtual, así como sistemas para el diseño de prótesis e implantes (Scharver, 2004: 33-38). En la psicológica terapéutica, se ha desarrollado el Sistema Terapéutico Virtual (STV) (Castañeda C. Y. R., Vázquez, F. E. G., 2011), el cual es una herramienta de apoyo en la Terapia de Acrofobia, Claustrofobia y Agorafobia. En el área de la ingeniería se han desarrollado sistemas para el diseño y fabricación de productos. Dentro del plano de la diversión, un sistema virtual muy conocido es el Second Life (Second Life, 2011), donde los actores (usuarios) pueden vivir virtualmente una segunda vida siendo la persona que deseen dentro del mundo virtual. Un ejemplo de aplicación didáctica de RV es el sistema Anatomía Humana Virtual (AHV) (Castañeda, C. Y. R., Espinosa, J. R. V., 2008), desarrollado para niños de primaria y dispone del cuerpo humano, del sistema digestivo, sistema óseo, sistema respiratorio y los sentidos (Figura 2).
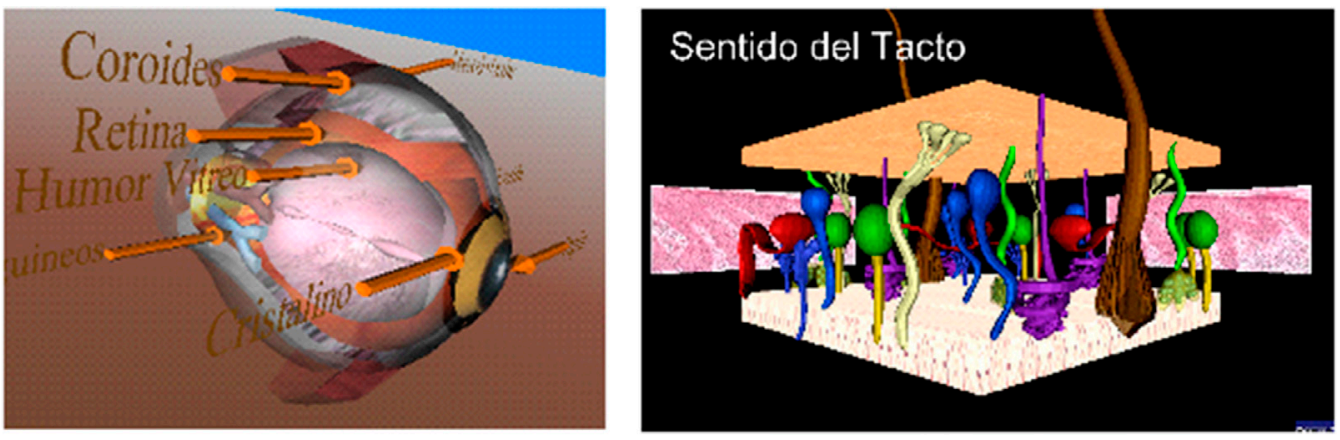

Figura 2: Sentido de la vista y tacto.

\section{Sistema CIGI}

Recientemente los autores (Medellín, H. I. C., Martínez, C. A. H., Espinosa, R. C. \& Castañeda, C. Y. R., 2011) han propuesto un novedoso Sistema Cinematográfico para Gente Invidente (CIGI) el cual considera el uso de la realidad virtual y los sistemas hápticos para añadir el sentido del tacto al cine. El sistema CIGI propuesto tiene como propósito crear un mundo virtual que puede ser explorado táctilmente 
por el invidente al mismo tiempo que escucha un espacio auditivo denominado cinecuento. Con base en el cinecuento se crea el mundo virtual que es explorado por la persona invidente por medio del sistema háptico que le permite sentir formas y texturas del ambiente virtual en el que se encuentre. A la integración del cinecuento con el mundo virtual se le ha llamado película virtual 3D.

La arquitectura general del sistema CIGI se muestra en la Figura 3. Como se puede observar, el sistema CIGI además de integrar el renderizado háptico, visual y auditivo, integra un módulo de producción cinematográfica en donde se definen las diferentes escenas virtuales y audios de la película con base en el guión cinematográfico. El motor de simulación realizará el renderizado háptico, visual y auditivo con base en la producción cinematográfica y el ambiente virtual correspondiente.

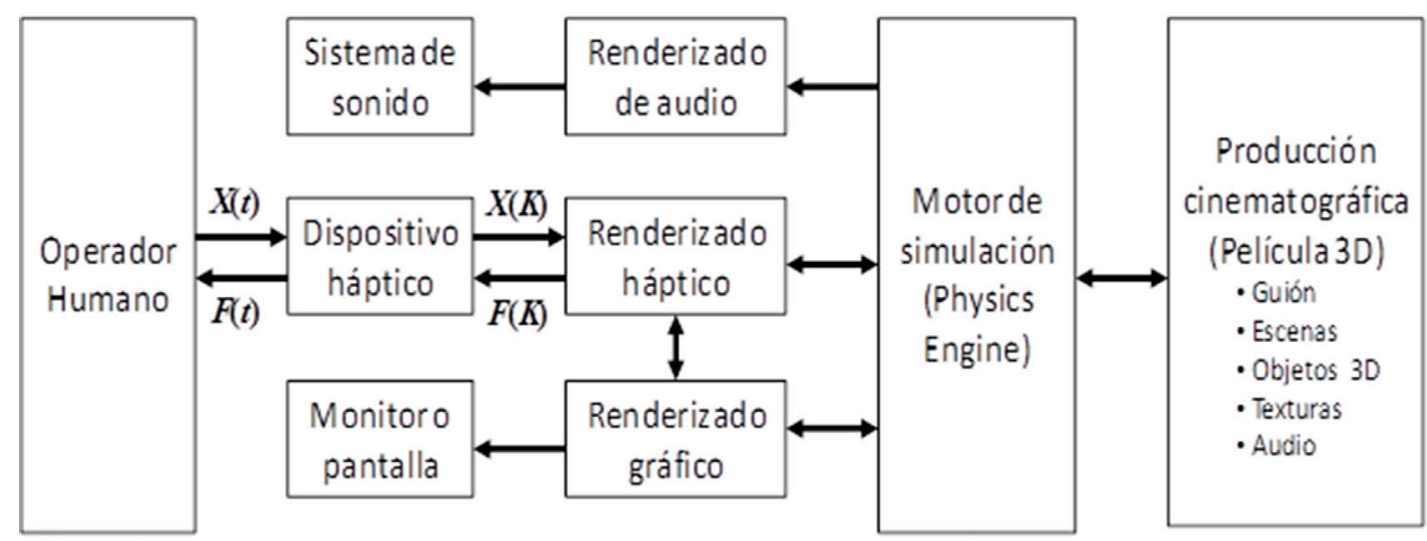

Figura 3: Arquitectura del sistema CIGI.

En el sistema CIGI el renderizado háptico se realiza utilizando un dispositivo háptico Phantom Omni de Sensable ${ }^{\circledR}$ (Figura 1a). Este dispositivo cuenta con seis grados de libertad de movimiento y tres grados de libertad de retroalimentación de fuerza. El sistema CIGI y la película interactiva-táctil 3D se muestran en la Figura 4. En la Figura 4b se puede apreciar una esfera azul la cual representa la posición del explorador háptico en el ambiente virtual. 


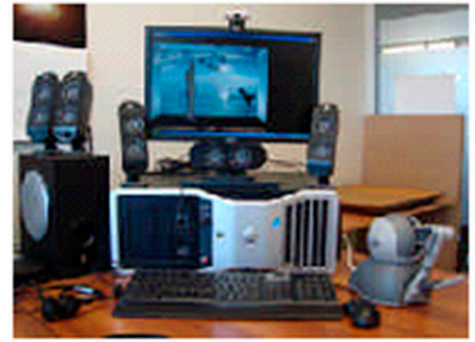

(a)

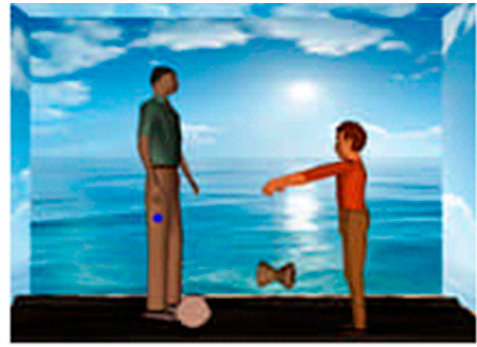

(b)

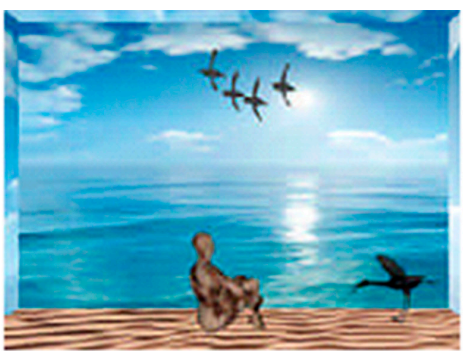

(c)

Figura 4: Sistema CIGI: a) equipo utilizado, b) y c) escenarios virtuales.

\section{Metodología experimental}

Para llevar a cabo la evaluación de la percepción virtual táctil y la generación de iconos mentales, se propusieron un conjunto de pruebas experimentales de exploración, apreciación y reconocimiento de objetos geométricos tridimensionales mediante el uso del dispositivo háptico y el sistema CIGI. Para ello se seleccionó un grupo de 8 personas: 4 con ceguera total, 3 con ceguera parcial y 1 débil visual, (Figura 5). Cabe mencionar que se tomaron en cuenta personas con diferentes niveles de invidencia con el fin de identificar la influencia del grado de invidencia en el reconocimiento táctil de los objetos tridimensionales. Por lo anterior, a ninguno de los participantes se le permitió ver la pantalla.

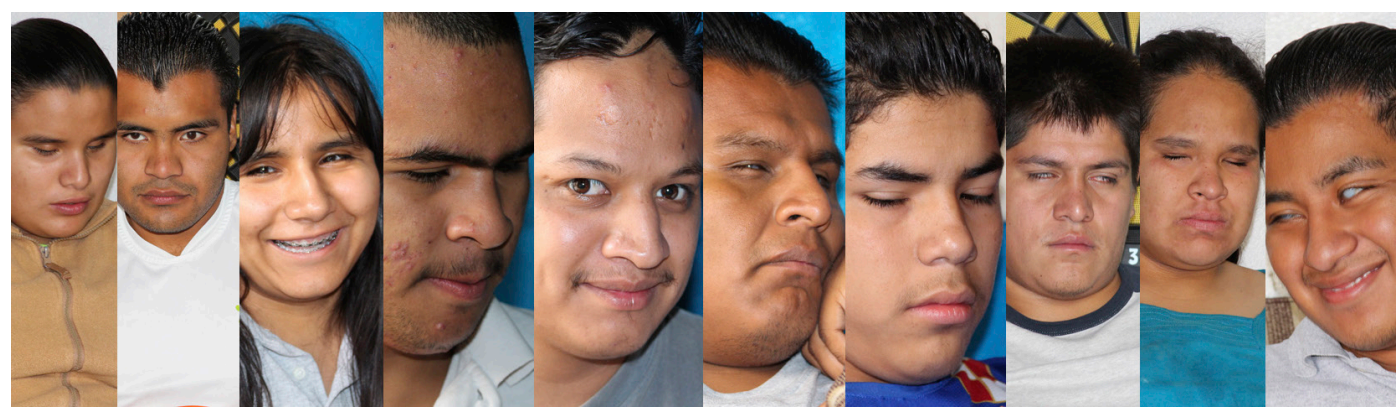

Figura 5: Participantes en las pruebas de evaluación.

\section{La metodología experimental fue la siguiente:}

1. Primero se situó a las personas invidentes en una sala en la cual se les dieron las indicaciones generales. 
2. Se seleccionaron cuatro objetos virtuales tridimensionales, previamente creados: un cubo, una esfera, un cilindro, y un cono truncado. El orden de exploración de los objetos fue distinto para cada participante con el fin de evaluar si a medida en que se familiarizan con el sistema, la identificación del objeto mejora.

3. A cada una de las personas se le solicitó realizar la exploración, apreciación y reconocimiento de los cuatro objetos virtuales mediante el dispositivo háptico y el sistema CIGI, (Figura 6). Para evitar algún tipo de nerviosismo o presión, a los participantes se les dio tiempo ilimitado para realizar las pruebas e identificar dichas figuras geométricas. A todos los participantes se les videograbó para el registro y posterior análisis de los resultados.

4. Al finalizar las pruebas, a cada uno de los integrantes se le realizó una serie de cuestionamientos en relación a sus percepciones sensoriales e iconos mentales.

\section{Resultados y percepciones virtuales táctiles}

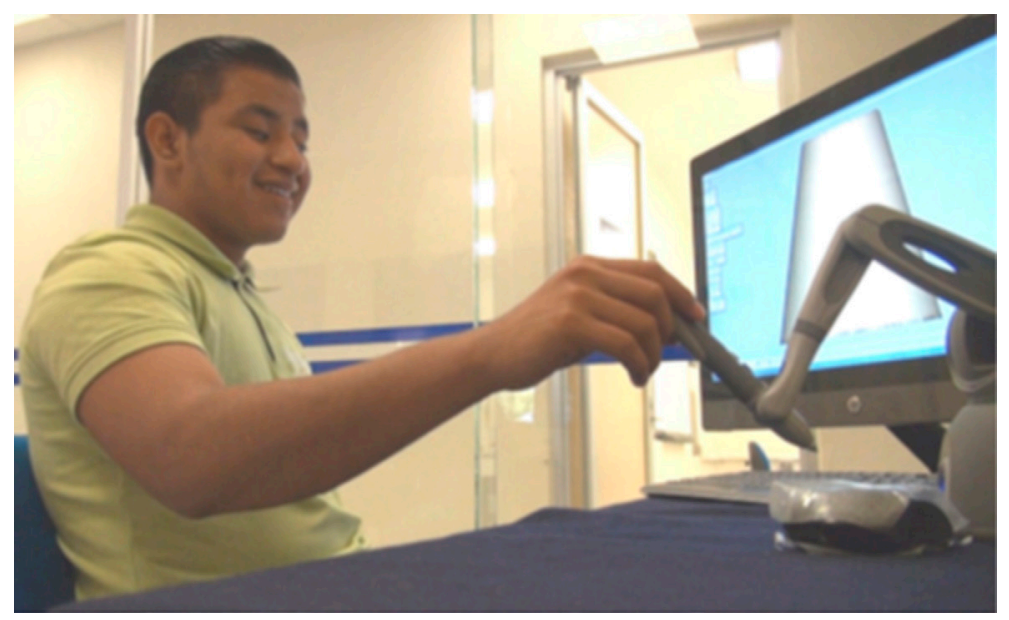

Figura 6: Pruebas de evaluación de la percepción virtual táctil. 
En la Tabla 1 se muestra el nombre de los participantes, su grado de invidencia $\mathrm{y}$ el orden en que se le presentaron los objetos tridimensionales.

\begin{tabular}{|c|c|c|}
\hline Participante & Grado de invidencia & Orden de los objetos explorados \\
\hline Hugo & Ceguera total & Cubo - esfera - cono - cilindro \\
\hline Alejandro & Ceguera parcial: ve sombras y bultos & Cubo - esfera - cono - cilindro \\
\hline Daniel & Ceguera parcial: ve sombras y bultos & Cono - esfera - cilindro - cubo \\
\hline Abel & Ceguera total & Cilindro - cubo - esfera - cono \\
\hline Fernando & Ceguera total & Cono- cubo - esfera - cilindro \\
\hline Lucero & Ceguera total & Cilindro - cubo - esfera - cono \\
\hline Rubiciel & Ceguera parcial: ve sombras y bultos & Cubo - esfera - cilindro - cono \\
\hline Jonny & Débil visual: lee a $3 \mathrm{~cm}$ de distancia & Esfera - cono - cilindro - cubo \\
\hline
\end{tabular}

Tabla 1: Participantes, grado de invidencia y orden de exploración

\subsection{Cubo}

En la Tabla 2 se muestran los resultados de la exploración táctil y reconocimiento del objeto cubo, así como el grado de dificultad que presentaron para identificarlo. De estos resultados se puede observar que los participantes esperaban sentir objetos 2D, cinco participantes expresaron sentir un cuadrado, dos de ellos mencionaron que el objeto era una caja; respuesta que se tomó en cuenta como correcta, debido a que la caja y el cubo están formados por seis caras. Solo uno de los participantes mencionó la palabra cubo como primera opción. Dos participantes

\begin{tabular}{|c|c|c|}
\hline Participante & Imagen mental del objeto percibido & Dificultad para reconocer el objeto \\
\hline Hugo & Rectángulo & Se le pierde el objeto y no lo identifica \\
\hline Alejandro & Cuadrado & En poco tiempo lo identifica \\
\hline Daniel & No se le mostró & No aplica \\
\hline Abel & Cubo & En poco tiempo lo identifica \\
\hline Fernando & Como un cuadrado; ¿una caja? & Tardó en reconocerlo \\
\hline Lucero & Rectángulo, cuadrado, puerta, cubo & Tardó en reconocerlo \\
\hline Rubiciel & Un cuadrado, un cubo & En poco tiempo lo identifica \\
\hline Jonny & Cuadrado, caja & Tardó en reconocerlo \\
\hline
\end{tabular}

Tabla 2: Resultados de la percepción virtual táctil de un cubo.

DOI: ri14.v12i2.695 | ISSN: 1697-8293 | Año 2014 Volumen 12 № 2 | ICONO14 
después de expresar que era o una caja o un cuadrado dijeron sentir un cubo. Sólo uno de los participantes no identificó el objeto.

\subsection{Esfera}

En la Tabla 3 se muestran los resultados de la exploración táctil y reconocimiento del objeto esfera, así como el grado de dificultad que presentaron para identificarlo. De los resultados se puede observar que los participantes pudieron identificar con mayor facilidad la esfera que el cubo. En el caso de la esfera, cuatro participantes expresaron sentir una esfera, un participante sintió una pelota, cuatro usuarios sintieron un círculo. En este caso a la persona débil visual se le permitió ver y tocar, por lo que no le difícil encontrar y reconocer el objeto, mostrando mayor precisión en sus movimientos.

\begin{tabular}{|c|c|c|}
\hline Participante & Imagen mental del objeto percibido & Dificultad para reconocer el objeto \\
\hline Hugo & Círculo & En poco tiempo lo identifica \\
\hline Alejandro & Círculo & En segundos lo identifica \\
\hline Daniel & Círculo, cilindro, pirámide, montaña & Tardó en reconocerlo \\
\hline Abel & Esfera & $\begin{array}{c}\text { Dudoso en su comentario, pero en poco } \\
\text { tiempo lo identifica }\end{array}$ \\
\hline Fernando & Círculo, cono & Tardó en reconocerlo \\
\hline Lucero & Círculo, esfera & Emocionada, en poco tiempo lo identifica \\
\hline Rubiciel & Círculo, pelota & \begin{tabular}{c} 
En poco tiempo lo identifica \\
\hline Jonny
\end{tabular} \\
\hline
\end{tabular}

Tabla 3: Resultados de la percepción virtual táctil de una esfera.

\subsection{Cilindro}

En el caso del cilindro los resultados se muestran en la Tabla 4. En este caso cuatro participantes lograron identificar el cilindro, un participante no sintió la figura en el primer intento, pero después de que habían pasado el resto de los participantes, se le dio una segunda oportunidad y volvió a sentir todas las figuras y fue entonces cuando identificó las figuras con más facilidad.

ICONO14 | Año 2014 Volumen 12 Nº | ISSN: 1697-8293 | DOI: ri14.v12i2.695 
Análisis y evaluación de la generación de iconos mentales en personas invidentes | 311

\begin{tabular}{|c|c|c|}
\hline Participante & Imagen mental del objeto percibido & Dificultad para reconocer el objeto \\
\hline Hugo & "No se me viene a la mente ninguna" & No lo identificó \\
\hline Alejandro & ¿Cilindro? & En poco tiempo lo identifica \\
\hline Daniel & Rectángulo, cilindro & En poco tiempo lo identifica \\
\hline Abel & Círculo, cuadrado, cono & $\begin{array}{c}\text { Se le explicó cómo era la figura y después } \\
\text { la identificó. Tardó en identificarlo. }\end{array}$ \\
\hline Fernando & Cuadrado, cono & No lo identificó \\
\hline Lucero & Círculo, esfera, cilindro & Tardó en identificarlo \\
\hline Rubiciel & Espiral, cilindro & En poco tiempo lo identifica \\
\hline Jonny & Triángulo, cilindro & En poco tiempo lo identifica \\
\hline
\end{tabular}

Tabla 4: Resultados de la percepción virtual táctil de un cilindro.

\subsection{Cono truncado}

El cono truncado tridimensional fue identificado con mayor dificultad por parte de los participantes debido a la complejidad de su forma, Tabla 5. Los resultados mostraron que dos usuarios identificaron el círculo menor en la parte superior delcono y el círculo mayor en la parte inferior, pero no imaginaron la forma completa. Sólo dos de ellos identificaron el cono truncado como "cono" o "pirámide".

\begin{tabular}{|c|c|c|}
\hline Participante & Imagen mental del objeto percibido & Dificultad para reconocer el objeto \\
\hline Hugo & "No se me viene a la mente ninguna" & No lo identificó \\
\hline Alejandro & ¿Cilindro? & En poco tiempo lo identifica \\
\hline Daniel & Rectángulo, cilindro & En poco tiempo lo identifica \\
\hline Abel & Círculo, cuadrado, cono & $\begin{array}{c}\text { Se le explicó cómo era la figura y después } \\
\text { la identificó. Tardó en identificarlo. }\end{array}$ \\
\hline Fernando & Cuadrado, cono & No lo identificó \\
\hline Lucero & Círculo, esfera, cilindro & Tardó en identificarlo \\
\hline Rubiciel & Espiral, cilindro & En poco tiempo lo identifica \\
\hline Jonny & Triángulo, cilindro & En poco tiempo lo identifica \\
\hline
\end{tabular}

Tabla 5: Resultados de la percepción virtual táctil de un cono truncado. 


\subsection{Expresiones y experiencias}

Las expresiones faciales que manifestaron los participantes a la percepción virtual táctil de objetos tridimensionales se muestran en la Tabla 6. De estos resultados se observa que muchas de las expresiones faciales fueron sonrisas, levantamiento de cejas y movimientos de manos que expresaban sorpresa. Todos los participantes manifestaron mucha emoción. A una de las personas débil visual no se le permitió ver la pantalla sino hasta el final del ejercicio, y al otro participante débil visual se le permitió ver sus movimientos sólo con el primer objeto que tocó, expresando que no se le dificultaba encontrarlo, sin embargo con la segunda figura no se le permitió ver el objeto y su dificultad para encontrarlo aumentó, pero conforme fue explorando otros objetos se familiarizó con el sistema y la dificultad disminuyó.

\begin{tabular}{|c|c|c|}
\hline Participante & Imagen mental del objeto percibido & $\begin{array}{c}\text { Dificultad para } \\
\text { reconocer el objeto }\end{array}$ \\
\hline Hugo & Sonrisas y risas, gestos de asombro & ¡Qué padre*, si se siente! \\
\hline Alejandro & $\begin{array}{c}\text { Muchas sonrisas, acercamientos a la pantalla, movi- } \\
\text { mientos acelerados de la mano, muy emocionado }\end{array}$ & ¡Qué bonito sentí! \\
\hline Daniel & $\begin{array}{c}\text { Asombro. Movimientos delicados. Duda al expresar la } \\
\text { figura de la que se trata. }\end{array}$ & \\
\hline Abel & $\begin{array}{c}\text { Se encuentra un poco perdido y su expresión facial lo } \\
\text { refleja. Sonríe y ríe cuando le hace hoyos a la figura }\end{array}$ & \\
\hline Fernando & $\begin{array}{c}\text { Trata de explorar la figura con movimientos bruscos, } \\
\text { ríe y expoción facial }\end{array}$ & \\
\hline Lucero & $\begin{array}{c}\text { Muy entusiasmada. Sonríe y ríe. Se sorprende al } \\
\text { explicarle que dentro de los objetos no hay nada }\end{array}$ & $\begin{array}{c}\text { ¡Esto está bien padre*! } \\
\text { ¡Se siente bien padre*! }\end{array}$ \\
\hline Rubiciel & $\begin{array}{c}\text { Se sorprende al saber que los movimientos de su mano } \\
\text { son en el aire, y que aun así siente las formas de las } \\
\text { figuras presentadas en pantalla. }\end{array}$ & $\begin{array}{c}\text { ¿Cómo? ¿Está dibujado } \\
\text { en la pantalla entonces? } \\
\text { ¡Increíble! }\end{array}$ \\
\hline Jonny & $\begin{array}{c}\text { Cuando se le permitió ver, exploraba los objetos a 3 } \\
\text { cm de distancia de la pantalla. Sonreía al momento de } \\
\text { la exploración. }\end{array}$ & ¡Pues si se siente! \\
\hline
\end{tabular}

Tabla 6: Expresiones faciales manifestadas ante la percepción virtual táctil. *padre es el coloquialismo mexicano de maravilloso. 
Al final de las pruebas se les preguntó a los participantes ¿Cómo fue tu experiencia al sentir figuras geométricas a través del sistema CIGI? Las respuestas obtenidas se muestran en la Tabla 7. De estos resultados se observa que la mayoría de los participantes gustó de la experiencia de sentir objetos 3D por medio del sistema CIGI. La experiencia de saber que tocaban lo que se veía en pantalla fue lo que más les emocionaba, como lo expresan con comentarios tales como el sentirse "sorprendidos por nunca haber sentido de esa manera". Asimismo, la mayoría de los participantes de forma exploratoria utilizaban el tacto activo con las dos manos para sentir la interface háptica en busca de un objeto real, sorprendiéndose de no encontrar objetos físicos frente a ellos, sino objetos virtuales presentes sólo en la pantalla del ordenador.

\begin{tabular}{|c|c|}
\hline Participante & Experiencias \\
\hline Hugo & $\begin{array}{l}\text { Pues más que nada quede sorprendido, porque nunca había sentido las figuras, } \\
\text { porque pues usted las puede estar viendo y yo no, y es interesante el cómo se } \\
\text { presentan. }\end{array}$ \\
\hline Alejandro & $\begin{array}{l}\text { Pues fue bien bonito porque nunca había sentido como se sienten las imágenes, } \\
\text { entonces fue como una experiencia nueva. }\end{array}$ \\
\hline Daniel & $\begin{array}{l}\text { Yo si le batalle un poco. Con eso de que se metía la pluma (el cursor) a la figura, si } \\
\text { le batallaba, pero si estuvo padre la experiencia. }\end{array}$ \\
\hline Abel & Si me gustó \\
\hline Fernando & Muy emocionado, me gustó mucho, aunque se me hizo dificil. \\
\hline Lucero & Se me hizo un poco dificil. \\
\hline Rubiciel & $\begin{array}{l}\text { Se me hizo un poco difícil porque uno como ciego está acostumbrado a tocar } \\
\text { imágenes pero en relieve, no tanto asi en espacio, ni dibujadas. Pero una vez que le } \\
\text { empiezas a practicar de cómo se utiliza la pluma en ese tipo de figuras, te das una } \\
\text { idea de cómo es, y si era complicado porque a veces te metías a la figura o se iba } \\
\text { arriba de la pantalla. }\end{array}$ \\
\hline Jonny & $\begin{array}{l}\text { No me es dificil encontrar la figura mientras sí las pueda ver. Cuando se me cubren } \\
\text { los ojos, tardo en reconocer los objetos pero si los identifico. }\end{array}$ \\
\hline
\end{tabular}

Tabla 7: Experiencias de personas ciegas y débiles visuales al percibir táctilmente objetos virtuales tridimensionales. 


\section{Análisis y discusión de resultados}

Del análisis de los resultados obtenidos de las pruebas experimentales, se puede decir que la percepción virtual táctil permite al invidente construir representaciones icónicas mentales del objeto 3D explorado. Conjuntamente se puede observar que los íconos mentales originados de la exploración táctil de objetos virtuales se asemejan mucho a los correspondientes de la exploración táctil de objetos reales. Mediante la percepción virtual táctil se puede hacer consciente al sujeto de las propiedades del objeto presentado. A pesar de que el reconocimiento de los objetos en algunos de los sujetos no fue inmediato, se observó que a medida que la persona se familiarizaba más con el sistema CIGI, la velocidad de exploración del ambiente virtual era más rápida.

Por otro lado, los patrones gráficos táctiles de las figuras geométricas 3D presentadas, ofrecen al tacto activo del ciego la información visual del entorno virtual, permitiendo que el sujeto represente mentalmente y exteriorice con la palabra oral lo que no puede percibir de manera visual. A través del tacto el ciego comprende que en el mundo exterior hay objetos asibles, con un nombre, una forma y un uso propio. Por lo anterior se puede decir que una persona invidente puede generar un ícono mental a partir de la percepción virtual táctil de un mundo virtual, comprendiéndolo y traduciéndolo en un ícono mental háptico.

\section{Conclusiones}

La aproximación a los medios masivos de comunicación se ha visto limitada a solamente el uso de imágenes visuales y auditivas, dejando a un lado la imagen táctil, la cual es de gran importancia para el caso de personas invidentes o débiles visuales. La adición de imagen táctil a los medios de comunicación resultaría de gran beneficio para las personas invidentes debido a que podrían comprender el mundo visual de los medios de comunicación.

En este trabajo de investigación se ha presentado el análisis y la evaluación del proceso de generación de iconos mentales en personas invidentes a partir de la percepción virtual táctil, creada mediante tecnologías modernas de realidad virtual

ICONO14 | Año 2014 Volumen 12 N² | ISSN: 1697-8293 | DOI: ri14.v12i2.695 
y sistemas hápticos. De los resultados obtenidos se observó que la percepción virtual táctil contribuye y mejora el proceso de construcción de íconos mentales en personas invidentes debido a que el sujeto explora e incorpora en sus experiencias recreativas la imagen táctil. El sistema CIGI utilizado en esta investigación, ofrece al tacto activo la información icónica del entorno virtual, para que el sujeto pueda acceder al mundo virtual y representar icono-mentalmente lo que no puede percibir visualmente. Así mismo, mediante este sistema es posible mejorar las representaciones mentales en gente invidente, ya que estas se adquieran en el momento en el que el sujeto incorpora como parte de sus experiencias recreativas la percepción táctil. Los patrones gráficos táctiles del sistema ofrecen al tacto activo la información visual del entorno virtual, tanto en forma como en textura. Las percepciones icónicas táctiles generan afectos y emociones que se interiorizan para la formación del icono mental.

Finalmente cabe mencionar que el presente trabajo forma parte de un proyecto de investigación cuyo propósito es lograr la incursión de la imagen táctil o ícono háptico en productos comunicativos, permitiendo a las personas percibir las propiedades geométricas de los objetos. En un futuro se espera que además de tocar los objetos virtuales, también sea posible proporcionar información sobre el peso y consistencia de los objetos al ser frotados, apretados y estirados.

\section{Referencias}

Aramburu, M. 0. (2004) Jerome Seymour Bruner: de la percepción al lenguaje. Revista Iberoamericana de Educación. (33), 1-18 ISSN: 1681-5653

Castañeda, C. Y. R., Espinosa, J. R. V. (2008). Realidad Virtual, una herramienta computacional para el estudio de Sistemas Orgánicos y los Sentidos del Tacto y Olfato a Nivel Primaria. Impulso (2). Tecnológico de Puebla.

Castañeda C. Y. R., Vázquez, F. E. G. (2011). Realidad Virtual, un apoyo en la Terapia de Acrofobia, Claustrofobia y Agorafobia. Memorias del VIII Congreso Internacional sobre Innovación y Desarrollo Tecnológico (CIINDET 2011). Cuernavaca Morelos, México.

Correa, M. P. (2008). Imagen táctil: Una representación del mundo. (Tesis inédita de Doctorado). Universidad de Barcelona, Barcelona

DOI: ri14.v12i2.695 | ISSN: 1697-8293 | Año 2014 Volumen 12 № 2 | ICONO14 
Gibson, J.J. (1966). The Senses Considered as Perceptual Systems. Boston: Houghton Mifflin. ISBN 0-313-23961-4

Gibson, J. J. (1974). La percepción del mundo visual (Primera Edición 1950). Buenos Aires: Infinito.

Grupo $\mu$ (1993). Tratado del signo visual - Para una retórica de la imagen. Madrid: Cátedra.

Katz, D. (1930). El mundo de las sensaciones táctiles. Madrid: Revista de 0ccidente, 255.

Medellín, H. I. C., Martínez, C. A. H., Espinosa, R. C. \& Castañeda, C. Y. R. (2011). "Desarrollo de un Sistema de Proyección de Películas Virtuales para Gente Invidente". Revista Impulso, revista arbitrada de las academias del Instituto Tecnológico de Puebla. México, Año 4, No. 2, Diciembre. Moles, A. (1991). La imagen, comunicación funcional. México: Trillas. Moreno, I. (2003). Iconos Hipermedia: La llave interactiva. ICONO, Revista de comunicación y tecnologías emergentes, Volumen 1(1), 122-133. Mass Media Press. ISSN: 1697-8293

Pacual-Leone, A., Amedi, A., Fregni, F. \& Merabet, L. B. (2005). The plastic Human Brain Cortex. Annual Review of Neuroscience 28, pp. 377-401. Piaget, J. (1946) Le development de la notion de temps chez lénfant, París, Press Universitaires de France (traducción castellana, El desarrollo de la noción del tiempo en Moles, Abraham (1991). La imagen, comunicación funcional. México: Trillas.

Piety, P. J. (2004) The Language System of Audio Description: An Investigation as a Discursive Process. Journal of Visual Impairment \& Blindness, Vol. 98 Issue 8 453-469.

Rosa, A., Ochaita E. (1993). Ceguera y desarrollo psicológico. Psicología de la ceguera. Madrid: Alianza Editorial.

Saussure de., F. (1998). Curso de Lingüística General. Doceava edición. Primera edición 1980. Distribuciones Fontamara. México.

Scharver, C., Evenhouse, R., Johnson, A. \& Leigh, J. (2004). Designing cranial implants in a haptic augmented reality environment, en Communications of the ACM, Vol. 47 (No. 8), August, pp. 33-38.

Second life. Recuperado de: http://secondlife.com/ [Consulta 2011, Noviembre 2]. 
Análisis y evaluación de la generación de iconos mentales en personas invidentes $\mid 317$

Snyder, J. (2002). Fundamentals of audio description. Tacoma Park, MD: Audio Description Associates.

\section{Agradecimientos}

Los autores agradecen al Consejo Nacional para la Cultura y las Artes (CONACULTA) de México, y a la SEP a través del programa PROMEP, por el apoyo financiero otorgado para la realización del proyecto.

DOI: ri14.v12i2.695 | ISSN: 1697-8293 | Año 2014 Volumen 12 NN$^{\circ} 2$ | ICONO14 